\title{
Simulations of an Underground Explosion in Granite
}

\author{
T.H. Antoun \\ O.Y. Vorobiev \\ I.N. Lomov \\ L.A. Glenn
}

This paper was prepared for submittal to the

American Physical Society

11th Topical Conference on Shock Compression of Condensed Matter

Snowbird, UT

June 27-July 2, 1999

June 14, 1999

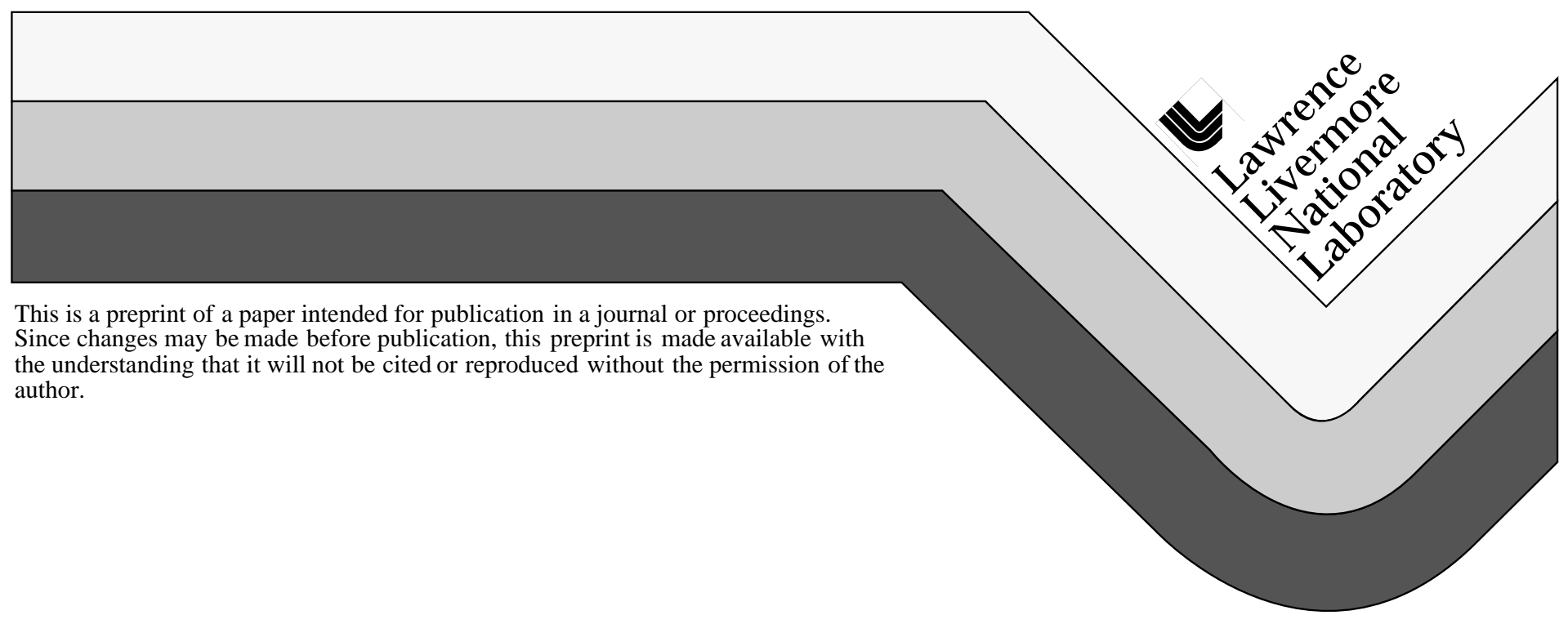




\section{DISCLAIMER}

This document was prepared as an account of work sponsored by an agency of the United States Government. Neither the United States Government nor the University of California nor any of their employees, makes any warranty, express or implied, or assumes any legal liability or responsibility for the accuracy, completeness, or usefulness of any information, apparatus, product, or process

disclosed, or represents that its use would not infringe privately owned rights. Reference herein to any specific commercial product, process, or service by trade name, trademark, manufacturer, or otherwise, does not necessarily constitute or imply its endorsement, recommendation, or favoring by the United States Government or the University of California. The views and opinions of authors expressed herein do not necessarily state or reflect those of the United States Government or the University of California, and shall not be used for advertising or product endorsement purposes. 


\title{
SIMULATIONS OF AN UNDERGROUND EXPLOSION IN GRANITE
}

\author{
Tarabay H. Antoun, Oleg Yu Vorobiev, Ilya N. Lomov, Lewis A. Glenn \\ Lawrence Livermore National Laboratory, Geophysics and Global Security Division, Livermore, CA 94550
}

\begin{abstract}
This paper describes the results of a computational study performed to investigate the behavior of granite under shock wave loading conditions. A thermomechanically consistent constitutive model that includes the effects of bulking, yielding, material damage, and porous compaction on the material response was used in the simulations. The model parameters were determined based on experimental data, and the model was then used in a series of onedimensional simulations of PILE DRIVER, a deeply-buried explosion in a granite formation at the Nevada Test Site. Particle velocity histories, peak velocity and peak displacement as a function of slant range, and the cavity radius obtained from the code simulations compared favorably with PILE DRIVER data.
\end{abstract}

\section{INTRODUCTION}

Simulating the behavior of granite under impact loading conditions requires the use of a constitutive model that includes the effects of bulking, yielding, damage, and porous compaction on the material response. In this paper, a constitutive model that incorporates these features is calibrated using static data; then it is used to perform 1D simulations of PILE DRIVER, an underground nuclear explosion detonated in the granitic Climax Stock of Area 15 at the Nevada test site [1]. The explosion was detonated at a depth of $462.8 \mathrm{~m}$ as shown in Figure 1. Data from the test included free field ground motion measurements made using velocity and acceleration sensors at ranges starting in the hydrodynamic region in the vicinity of the explosive cavity and extending out more than $1000 \mathrm{~m}$, well beyond the elastic radius.

\section{MODEL DESCRIPTION}

The rock behavior is described using an elastic-viscoplastic model, coupled with a timedependent damage model for the deviatoric behavior, and a Mie-Grüneisen equation of state, coupled with a porous compaction model and a bulking model, for the volumetric behavior. The model is described in more detail in a companion paper [2], here we only provide a summary of its main features.

The deviatoric model is isotropic and it describes the initial yield behavior with a pressure-dependent yield criterion. Initial yielding is followed with a plastic strain hardening phase which persists until the loading path intersects the failure surface.

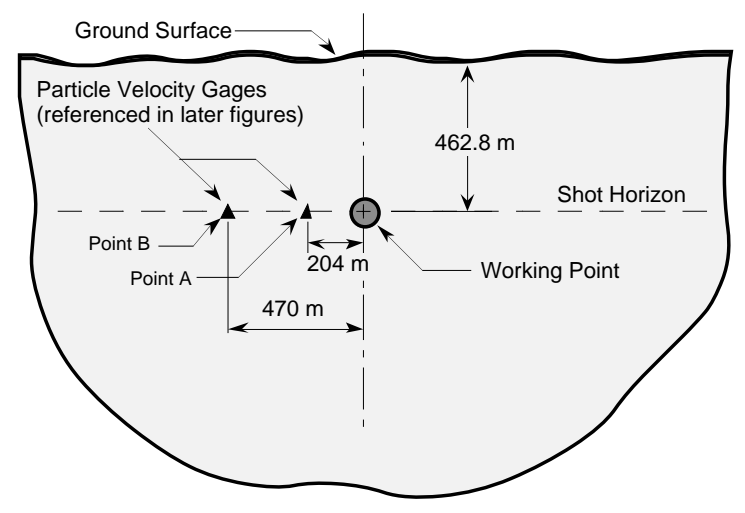

FIGURE 1. Configuration of the PILE DRIVER experiment showing the locations of two radial particle velocity gages deployed during the test. 
The post-failure behavior is described with a damage model similar to the Tuller-Butcher model [3] for spall damage. With this model, the damage parameter, $\Omega$, is computed using the relation

$$
\Omega=\frac{1}{A} \int\left(\sigma_{\max }-\sigma_{t h}\right) d t
$$

where $\sigma_{\max }$ is the most compressive principal stress, $\sigma_{t h}$ is the threshold stress for damage growth, and $A$ is a normalizing constant that renders $\Omega$ dimensionless. During the post-failure regime, the strength of granite is gradually diminished until a minimum prescribed value is attained.

The Mie-Grüneisen equation of state, which describes the behavior of non-porous granite ${ }^{1}$, is supplemented with an analytic porous compaction model that describes the relationship between pressure and porosity. Also included in the volumetric behavior description is a dilatancy model which relates bulking to plastic deformation in such a way as to ensure thermomechanical consistency with the second law of thermodynamics.

The model is implemented in VGR, a twodimensional Eulerian code with adaptive mesh refinement capabilities.

\section{SIMULATION RESULTS}

Our investigation included both static and dynamic simulations. Statically, the behavior of granite in triaxial compression was simulated at different levels of confining pressure. The numerical simulations closely resembled a series of experiments performed by Schock et al. [4] to examine the yield, bulking and failure characteristics of Climax Stock granodiorite, the same rock formation where PILE DRIVER was detonated. These static simulations were used to determine the material parameters for the yield and bulking models. As indicated in [2], the simulation results are in good agreement with the static data.

With the model calibrated based on the static data, we performed a series of 1D, spherically

\footnotetext{
${ }^{1}$ We performed some simulations using a tabular equation of state for granite, but this did not seem to have a significant effect on the results.
}

symmetric, PILE DRIVER simulations. The explosive source was approximated by depositing energy uniformly in a cavity containing an ideal gas with a density equal to that of granite, and a ratio of specific heats of 1.17 . In the simulations, the post-failure damage model parameters were varied in an effort to obtain a reasonable fit to the PILE DRIVER data (the post-failure model was not exercised in the static simulations because the static measurements did not include post-failure data). However, an adequate fit to the data could not be achieved using the statically-calibrated model. To improve the agreement between the simulation results and the PILE DRIVER data, it was necessary to lower the strength of granite in the dynamic simulations as shown in Figure 2.

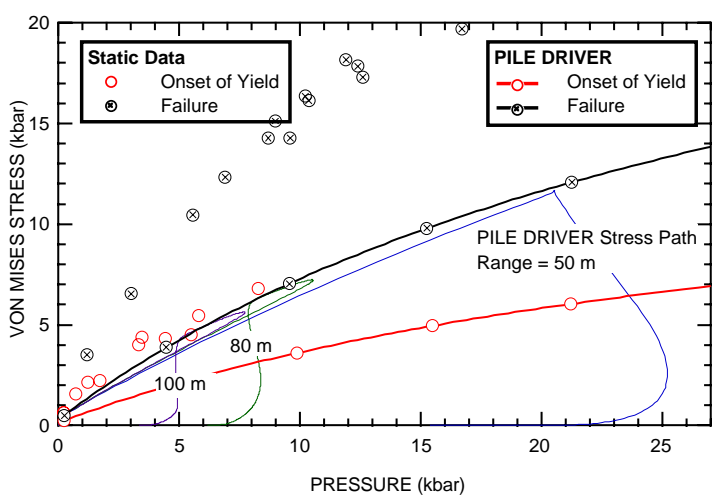

FIGURE 2. Yield and failure surfaces used in the static and dynamic simulations. Stress paths from the PILE DRIVER simulation at three different ranges are also shown.

The yield and failure stresses measured statically using relatively small, defect-free samples had to be reduced by about $50 \%$ to satisfactorily reproduce the dynamic data. This finding is in line with experimental data that show the strength of granite and other geologic materials to be size-dependent, decreasing with increasing specimen dimensions.

Fig. 2 also shows several stress path trajectories experienced by the material at different ranges away from the charge cavity. Each trajectory consists of a monotonic loading path during which several inelastic processes take place including yielding, compaction and bulking. As the stress path reaches the failure surface, damage begins to develop causing the material to unload. The unloading path is a complex 
function of damage kinetics which depend on the stress magnitude and the duration of load application. It is shown in Fig. 2 that at higher stress (50-m-range), damage develops quickly and the loading path falls rapidly off the failure surface. At lower stress, damage develops at a slower rate, thus allowing the material to stay on, or near the failure surface longer, which gives rise to the loops observed in the stress trajectories at ranges of $80 \mathrm{~m}$ or greater.

Figures 3 and 4 compare simulation results with measurements of radial particle velocity histories and corresponding displacement histories at ranges of $204 \mathrm{~m}$ and $470 \mathrm{~m}$ from the center of the charge. These two positions correspond to points $A$ and $B$ in Fig. 1. The velocity waveforms are characterized by a positive phase representing the outward motion of the rock, followed by a rebound phase during which the material contracts and displaces radially inward toward the explosive source.

Analysis of the simulation results made it possible to associate processes in the constitutive model with measured waveform features. For instance, the peak particle velocity attenuation as a function of scaled slant range, shown in Figure 5, is strongly influenced by porous compaction (in addition to its characteristic dependence on the divergent flow field). This attenuation is further complicated by the yielding and damage processes that determine the residual strength of the material behind the shock front. A stronger material allows

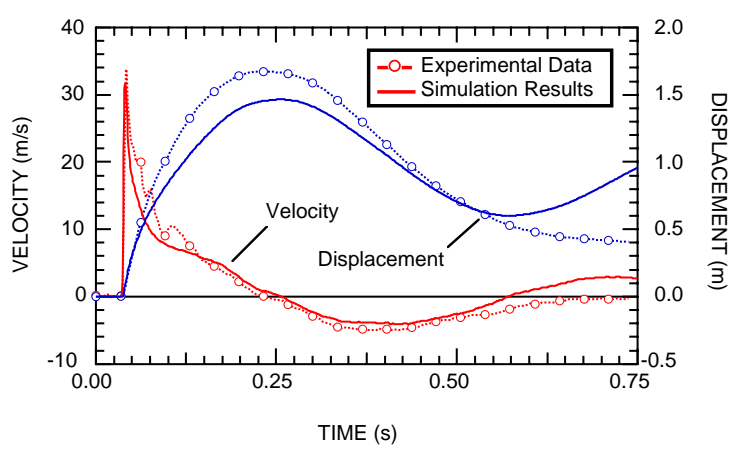

FIGURE 3. Comparison of simulated and measured radial velocity and displacement histories at a slant range of $204 \mathrm{~m}$ (Point A in Figure 1).

more of the release waves emanating from the explosive source to catch up with the main shock front and cause it to attenuate at a faster rate, thereby diminishing the peak velocity amplitude.

The width of the positive phase of the velocity waveform is strongly dependent on bulking. The increased volume associated with bulking causes the pressure in the material to be higher than it would be if bulking was suppressed. The work done by this higher pressure causes an increase in the outward displacement of the rock. This effect is manifested as a widening of the positive phase of the simulated velocity waveforms. It is also manifested as an increase in the peak displacement observed at various ranges away from the explosive source. The peak displacement attenuation is depicted in Figure 6. As shown, the simulation results are in agreement with the data from PILE DRIVER, and they follow the same trend as several other spherical wave experiments in granite.

The rebound phase in the velocity records is largely due to yielding and damage. As the main wave propagates outward from the source, the material behind the shock front first yields, then fails due to the accumulation of damage. The damaged region encompasses a portion of the flow field nearest the charge cavity, while the yielded region extends further out into the flow field. Our simulations show that the material behavior during the rebound phase is strongly influenced by the impedance mismatch at the interface between the yielded and damaged regions: the larger the mismatch, the more prominent the rebound.

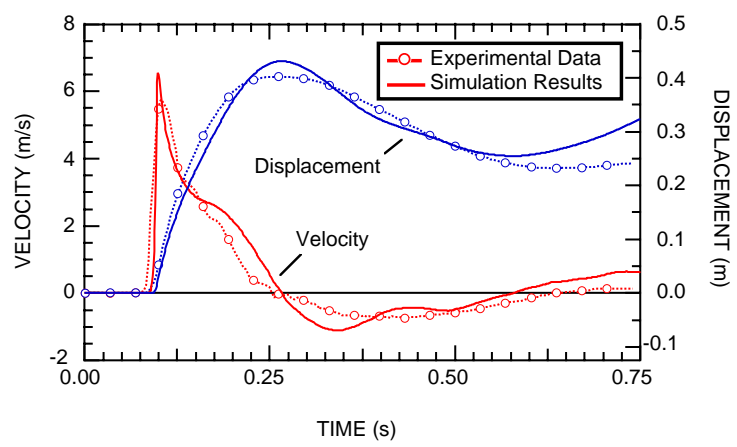

FIGURE 4. Comparison of simulated and measured radial velocity and displacement histories at a slant range of $470 \mathrm{~m}$ (Point B in Figure 1). 


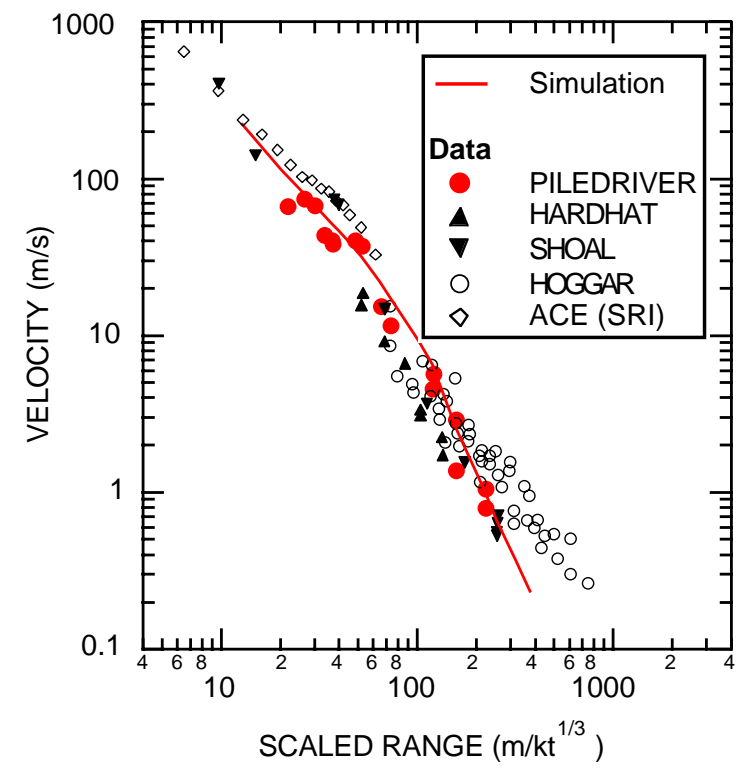

FIGURE 5. Comparison of simulated peak velocity attenuation with measurements from several spherical wave experiments in granite.

The motion of the cavity boundary was monitored throughout the simulation. The period of cavity oscillation was found to depend on the size of the damaged region. The simulated cavity size was also influenced by damage, and it agreed well with the measured values of between 40.1 and $44.5 \mathrm{~m}$.

\section{SUMMARY}

This paper reported progress in our ongoing effort to characterize the behavior of granite under impact loading conditions. Test data, in the form of velocity histories, peak velocity and peak displacement as a function of slant range, and cavity radius compare favorably with the results of simulations performed assuming that the granite in the PILE DRIVER testbed (i.e., large scale) is weaker than is indicated by laboratory measurements on relatively small $(2 \mathrm{~cm})$ and defect-free samples. This finding is in line with experimental data that show the strength of granite and other geologic materials to be sizedependent, decreasing with increasing specimen dimensions. Present and future efforts are focused on further constraining the model

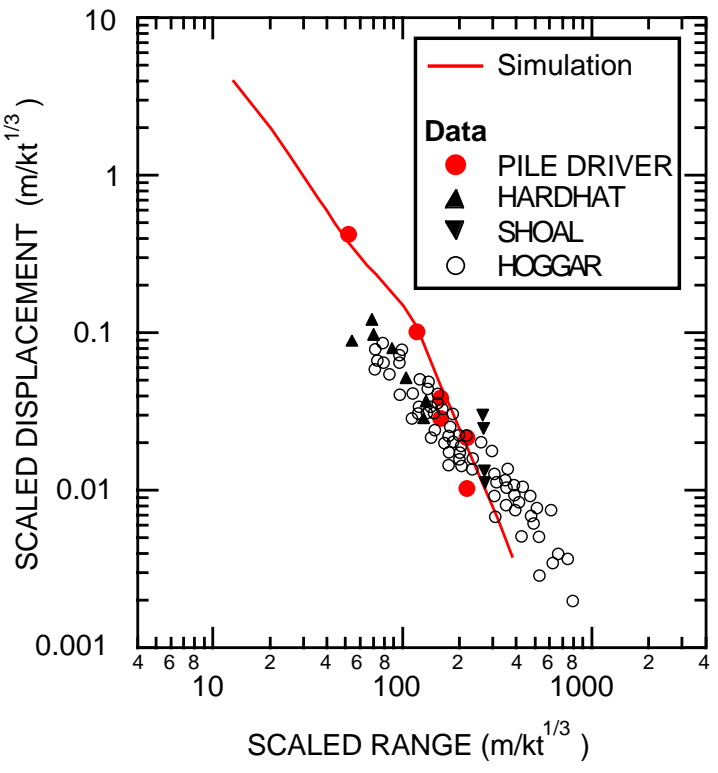

FIGURE 6. Comparison of simulated peak displacement attenuation with measurements from several spherical wave experiments in granite.

using static data, investigating the effects of surface reflections using 2D simulations, and using the model to investigate scaling effects associated with underground explosions in granite.

\section{ACKNOWLEDGMENTS}

Work performed under the auspices of the U.S. Department of Energy by the Lawrence Livermore National Laboratory under Contract W-7405-ENG-48.

\section{REFERENCES}

1. Perret, W. R., 'Free Field Ground Motion in Granite,' Report No. POR-4001, Sandia Laboratory, Albuquerque, New Mexico (1968).

2. Vorobiev, O. Y., Antoun, T., Lomov, I., and Glenn, L., 'A Strength and Damage Model for Rock Under Dynamic Loading,' to be published in the present proceedings.

3. Tuller, F. R., and Butcher, B. M., Int. J. fract. Mech., 4(4), 431-437 (1968).

4. Schock, R. N., Heard, H. C., and Stephens, D. R., J. Geophys. Res., 78(36), 5922-5941 (1973). 